\title{
Lateral Second Obtuse Marginal Branch Artery
}

National Cancer Institute

\section{Source}

National Cancer Institute. Lateral Second Obtuse Marginal Branch Artery. NCI Thesaurus.

Code C102311.

The lateral branch distal to a bifurcation of the second obtuse marginal artery. 